\title{
Energy resource efficient designs of small-sized water circulating cooling devices
}

\author{
K.E. Bondar* iD, N.S. Shulaev ID, S.P. Ivanov iD, S.V. Laponov iD \\ Ufa State Petroleum Technological University, Sterlitamak Branch, Sterlitamak, Russia \\ * Contacts: e-mail: kristina88_08@mail.ru
}

\begin{abstract}
Introduction. To use natural sources in rational way, plantsof continuous cooling of closed systems of recycling water supply are used. The paper presents designs of small-sized devices for recycling water cooling which are energy resource effective due to twisted motion of air flow, moving countercurrent to the cooled water. Heat and mass transfer is a nanotechnological process that occurs at the intermolecular level. Methods and materials. Countercurrent mini cooling towers are widely used in all industries, but there are some disadvantages, the main of which is the insufficient interaction time of the moving phases. Screw motion of air flow is created by the tangential supply of cooling air in the bottom part of cylindrical small-sized cooling tower. The rate of rotary motion decreases as air flow moves up in cooling towers, and vertical parameter of the rate - increases. Such scheme of the air flow motionmakes it possible to decrease average vertical parameter of the rate and to increase phases contact time. Laboratory research. To determine the technological and hydroaerothermal characteristics, as well as to estimate the efficiency of cooling recycled water, and to carry out mass-heat exchange at the intermolecular stagean experimental facility of small-sized cooling tower with twisted air flow has been developed. Conclusions. In accordance with the exponential law it is shown that the rotational component decreases at increasing height, and in accordance with the power law the vertical component increases component with the exponent $\sim 1,79$. It is determined that moisture content $x$ and air temperature $t_{v}$ in the volume of the height of the sprinkler varies according to a power law, in particular for a screw cooling tower proportionally $x \sim h^{0,83}, t_{\mathrm{B}} \sim h^{1,25}$. It was determined that the coefficients of mass transfer $\beta_{x v}$ and heat transfer $a_{v}$ of a mini cooling tower with twisted air flow at the intermolecular level with equal irrigation densities are $20 \%$ higher than the coefficients of a mini cooling tower with counter-current flow. Also it has been determined experimentally a dependence of aerodynamics resistance coefficient of the twisted irrigator of the cooling tower on criterium Refor air flow, and it was determined that it decreases like $R e^{-K_{2}}$ as the exponent $K_{2}$ varies in the range $0.114 \div 0.193$ depending on the irrigation density.
\end{abstract}

KEYWORDS: nanotechnologies, recycled water cooling, cooling tower, mini cooling tower, sprinkler, aerodynamics.

FOR CITATION: Bondar K.E., Shulaev N.S., Ivanov S.P., Laponov S.V. Energy resource efficient designs of small-sized devices for recycled water cooling. Nanotechnologies in construction. 2020;12(6): 339-348. Available from:doi: 10.15828/2075-85452020-12-6-339-348.

\section{INTRODUCTION}

$\mathrm{T}$ o provide rational use of natural resources under scarcity of natural sources, one needs to use facilities of continuous cooling of closed systems of recycled water supply. To implement cooling towers is practically the only method of dissipation of low-grade energy into the atmosphere at growing concentration of industrial production [1].

Cooling towers are used in almost all industries, especially its widely used at energy, chemical, oil refining, metallurgical and other industries, since today the removal of low-grade heat at the intermolecular level with the help of cooling towers is the cheapest way to save at least $95 \%$ of fresh water [2].

Since "nanotechnologies are technologies for manipulating matter at the atomic and molecular stage", and the process of heat and mass transfer in cooling towers runs at the intermolecular stage, it can be considered as a nanotechnological process.

A cooling tower is a device that operates on the principle of counterflow of water and atmospheric air [3]. It is of great importance to search scientific and technical solutions which would allow equipping industrial enterprises with local systems of recycled water cooling (mini cooling towers) which are more mobile, serve specific techno-

(c) Bondar K.E., Shulaev N.S., Ivanov S.P., Laponov S.V., 2020 
logical installations or plants, are less energy intensive, efficient and environmentally friendly. Application of local systems removes the need of long pipeline, also bulkiness of structures, minimizes emissions into the atmosphere.

\section{METHODS AND MATERIALS}

At the present several types of mini cooling towers are available. They are being actively introduced into production, however one should note some significant disadvantages which don't allow regarding them as a replacement of large systems: low heat removal (due to the countercurrent interaction of the ascending steam-air flow and the falling water flow, which does not provide sufficient time for heat and mass transfer during phase contact); low efficiency of contact devices (sprinklers); large dripnose [4-8].

The main reason of low efficiency of small-sized devices is short contact time of the cooling air flow and the cooled water flow, which leads to low heat removal values. It is due to small parameters in comparison with fan and tower cooling towers and counter-current mode of interaction of heat exchanging phases.

It is proposed to use a twisted motion of the ascending air flow, which will significantly increase the phase contact time and increase the efficiency of the heat and mass transfer process at the intermolecular stage. The spiral interaction of water flow and air flow leads to increase

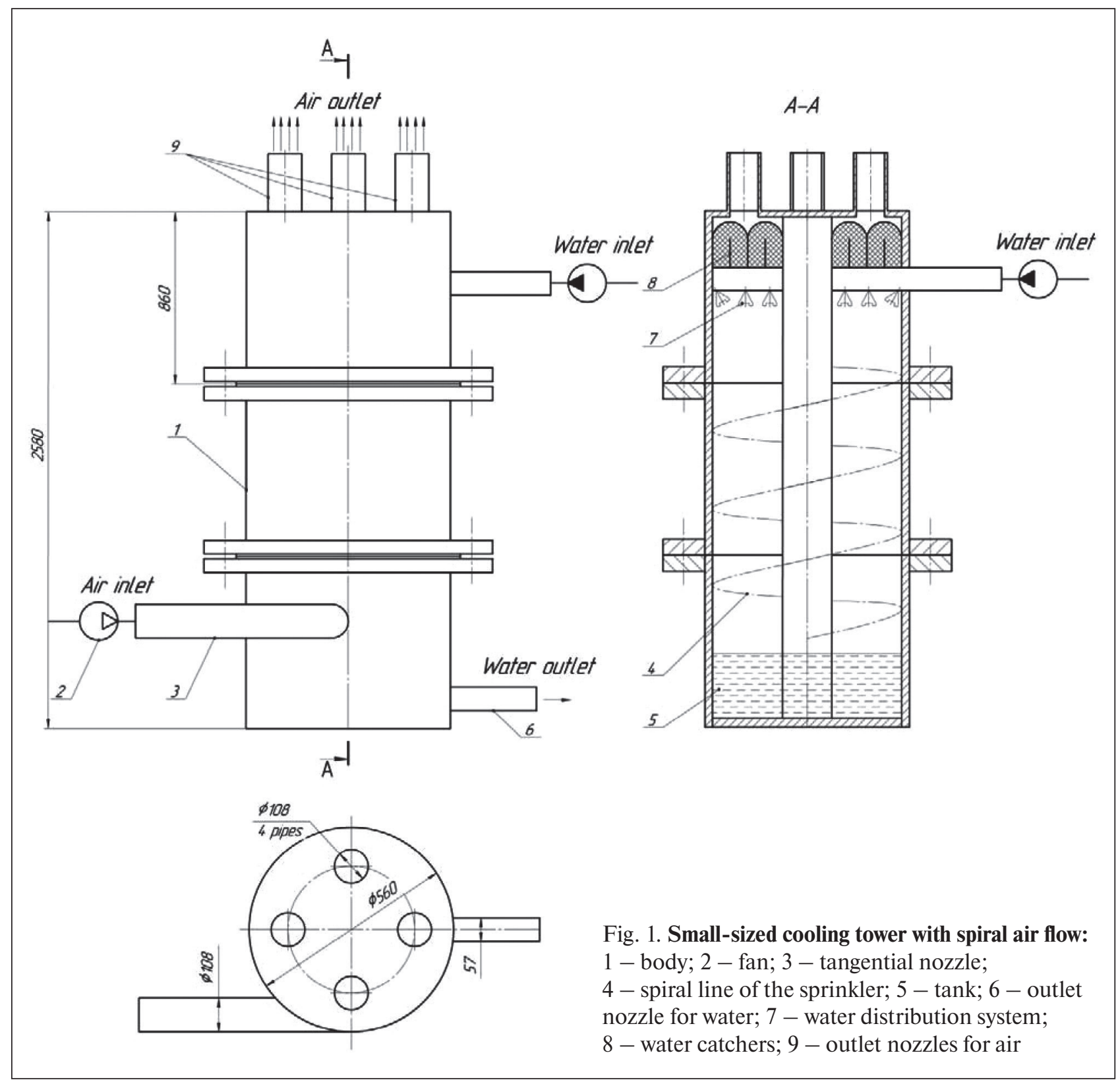


of contact time of vapor and air phases and decrease of cooled water. Figure 1 shows a diagram of a small-sized cooling tower with a spiral air flow, where the sprinkler is made of layers of cylindrical polymer cellular pipes and laid along a spiral line 4 coaxially with the helical air flow line.

The water, heated in the technological process from closed system, is supplied to water distribution system, and then it isevenly distributed in the volume of the spiral sprinkler, where heat and mass exchange of the water and air screw flow created by the fan runs at the intermolecular stage.

The tangential supply of the cooling air flow causes a spiral movement of the gas phase in the bottom part cy- lindrical small-sized cooling tower. As the air flow moves up, the speed of the rotational movement decreases, and the vertical movement increases. In the upper part of the cooling tower, there is almost no rotation of the air flow and it moves progressively vertically upwards. Such provision of the movement makes it possible to decrease in average the vertical parameter of the rate and to increase phases contact time

The spiral small-sized mini cooling tower with fins is a modification of this construction (Figure 2), which consist of a body with consistently arranged air catcher, water distributor and sprinkler of layers laid along a spiral line of cylindrical polymeric cellular pipes, with a fan installed in the bottom part, a drainage tank. On the inner side

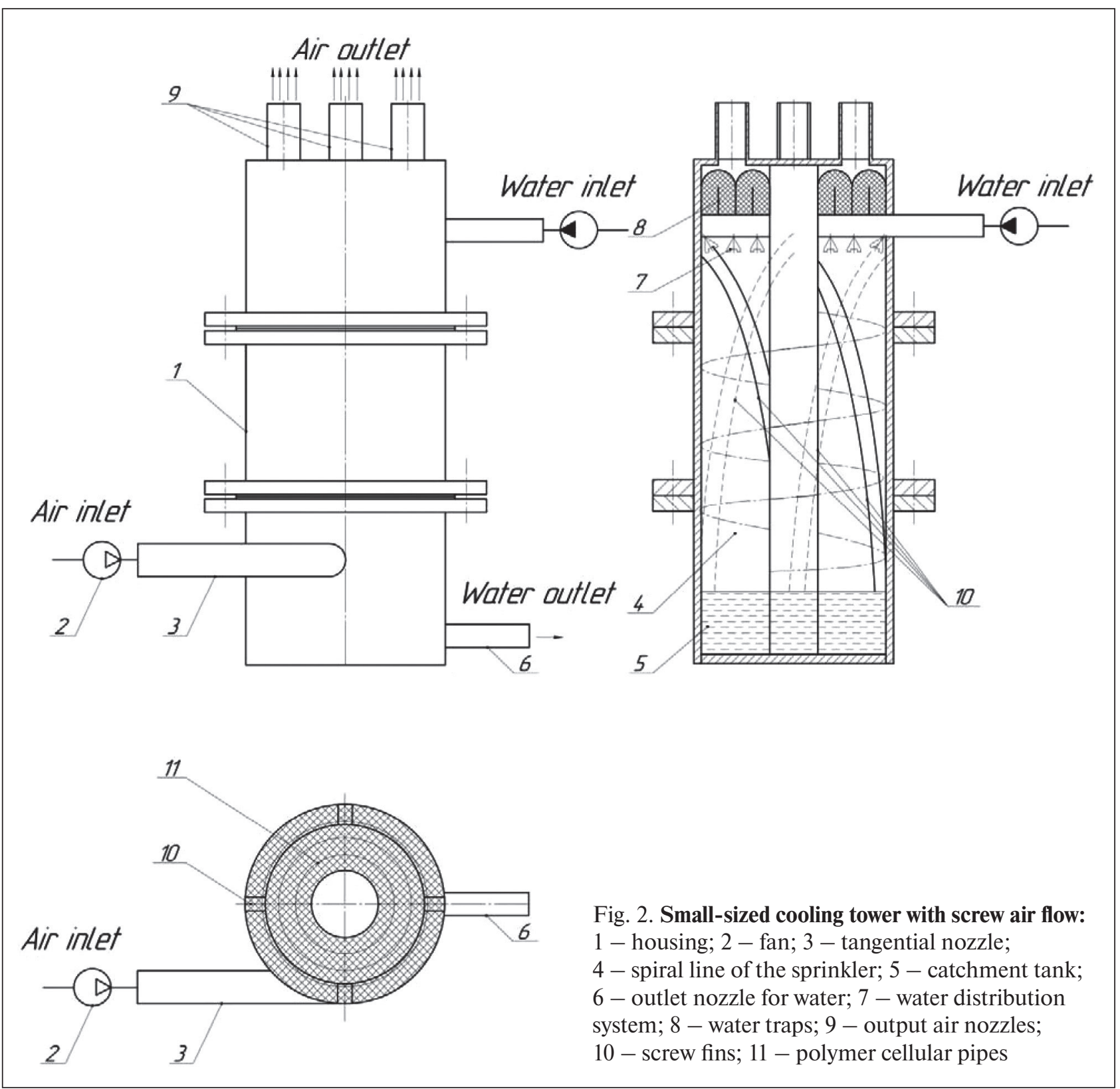


of the cylindrical surface of the cooling tower is installed in the direction perpendicular to the lines of plastic pipes, helical fin 10 consisting of an even number (four or more) of helical strips of width 0.1 diameter towers, offset from each other by the angle $(2 \pi / n) \mathrm{rad}$, where $n$ is the number of helical stripes, with a pitch of a spiral in two heights of the cooling tower the cooling tower.

Water from recycled system, heated in the technological process go to water distribution system 7, thanks to which is evenly distributed over the cross-section of the helical line of the sprinkler 4 and over the surface of the cellular pipes 11 of the sprinkler, on which the heat exchange of the water flow with the helical air flow forced by the fan 2 takes place. Water flows down on the sprinkler, where it is cooled under the drip-film flow mode and then enters the water catchment tank 5 . The efficiency of the proposed cooling tower is due to the fact that a screw fins 10 passes through the entire working volume of the cooling tower, which helps to maintain the rotational movement of the air flow, increasing the contact time of the cooling air and the cooled water flows.

Thus, the proposed designs of small-sized devices are an alternative to the existing bulky water circulation systems and mini-towers with countercurrent phase movement. The proposed designs will reduce drop loss by increasing the efficiency of contact devices [9-13] and the low temperature of the cooled water, increasing the contact time of the phases.

To estimate the change in the rotational and translational components of the velocity along the height of the cooling tower, we use the equation of continuity of the flow [14] in a cylindrical coordinate system, the $z$ axis of which coincides with the axis of symmetry of the cylindrical cooling tower. In a cylindrical coordinate system with impenetrable walls, the radial component of the velocity is negligible $\approx 0$.

$$
\frac{1}{r} \frac{\partial}{\partial \theta} \vartheta_{\theta}+\frac{\partial}{\partial z} \vartheta_{z}=0
$$

where $r$ - is the distance from the axis of rotation, $\mathrm{m}$; $\vartheta_{\theta}$ - rotational component of the speed, $\mathrm{m} / \mathrm{s}$;

$\vartheta_{z}$ - vertical component of the speed, $\mathrm{m} / \mathrm{s}$.

The rotational speed is determined by the ratio:

$$
\vartheta_{\theta}=\omega \cdot r
$$

where $\omega-$ is the angular velocity of rotation of the air flow, rad/s;

Taking into account that $\vartheta_{z}$ component of air rate in the inlet of the cooling tower is zero, and grows with increasing altitude, we will seek a solution to equation (1) in the form:

$$
\vartheta_{z}=\frac{4 G_{v}}{\pi D^{2}}\left(\frac{z}{H}\right)^{n},
$$

where $G_{v}-$ is the volumetric air flow, $\mathrm{m}^{3} / \mathrm{s}$;

$D$ - diameter of the cooling tower, $\mathrm{m}$;

$H$ - height of the cooling tower, m;

$n-$ the exponent.

Substituting expressions (2) and (3) into the continuity equation, we obtain:

$$
\frac{\partial \omega}{\partial \theta}+\frac{4 n G_{v}}{\pi D^{2}} \frac{z^{n-1}}{H^{n}}=0 .
$$

By entering the notation $\mathrm{A}=4 G_{v} / \pi D_{2}$ and taking into account that $\partial \theta=\omega \partial \tau$ ( $\tau-$ the time of the air flow in the cooling tower), equation (4) takes the form:

$$
\frac{1}{\omega} \frac{\partial \omega}{\partial \tau}+\frac{A n}{H^{n}} z^{n-1}=0 .
$$

By solving equation (4), you can determine the change in the angular velocity of the air flow along the height of the cooling tower and the time spent in it:

$$
\omega=\omega_{0} e^{-\frac{A n z^{n-1}}{H^{n}} \tau},
$$

where $\omega_{0}-$ is determined by the design parameters of the cooling tower:

$$
\omega_{0}=\frac{4 G_{v}}{\pi d^{2} R} .
$$

where $d-$ is the diameter of the inlet pipe, $\mathrm{m}$;

$R$ - radius of the cooling tower, $\mathrm{m}$.

As can be seen from the last relation, as you move up the cooling tower, the angular velocity of the air flow decreases exponentially. Taking in account that $z=H \omega \rightarrow 0$, will determine characteristic time of air flow staying in the cooling tower [15].

In accordance with determination of time of transient processes we will get:

$$
\omega(z=H)=\frac{\omega_{0}}{e^{5}} \rightarrow 0 .
$$

In this case, the characteristic residence time of the air flow in the cooling tower is determined by the ratio:

$$
\tau=\frac{5 H}{A n}=\frac{5 \pi D^{2}}{4 G_{v} n} .
$$

Knowing the staying time of the air flow in the cooling tower, you can determine the average height of the longitudinal speed of movement:

$$
\left\langle\vartheta_{z}\right\rangle=\frac{H}{\tau}=\frac{A n}{5}
$$

On the other hand, the average altitude speed can be calculated using the formula:

$$
\left\langle\vartheta_{z}\right\rangle=\frac{1}{H} \int_{0}^{H} \vartheta_{z}(z) d z=\frac{1}{H} \int_{0}^{H} A\left(\frac{z}{H}\right)^{n} d z=\frac{A}{n+1} .
$$


Comparing expressions (10) and (11), we obtain the relation for determining the exponent of $n$ :

$$
\frac{n}{5}=\frac{1}{n+1}
$$

from which it follows that $n=1.79$.

Thus, in a cooling tower with tangential input of cooling air, a "screw" movement of the air flow is realized, while the angular speed of rotation decreases along the height of the cooling tower according to the exponential law (6), and the linear speed increases with increasing $z$ coordinate according to the power law:

$$
\vartheta_{z} \approx \frac{4 G_{v}}{\pi D^{2}}\left(\frac{z}{H}\right)^{1,79}
$$

Taking into account that staying time of air flow in cooling tower is connected with $z$ coordinate by the formula $\tau=z /\langle\vartheta\rangle$, we can to convert the ratio (6) to determine the angular velocity of rotation:

$$
\omega=\omega_{0} e^{-5\left(\frac{z}{H}\right)^{n}}
$$

\section{LABORATORY RESEARCHES}

To determine the technological and hydroaerothermal characteristics, as well as to evaluate the efficiency of cooling recycled water, an experimental installation "small-sized cooling tower" with a screw air flow was developed [16, 17].

Aerodynamic tests were carried out to determine the coefficient of aerodynamic resistance $\zeta$ of the sprin- kler for a small-sized cooling tower with a screw flow and a counter-current mini-tower, and depending on the technological parameters. Hydroaerothermal tests were performed to determine changes in the temperature of circulating water and the coefficients of heat and mass transfer at the intermolecular level.

The experiments were carried out at irrigation densities up to $q=12 \mathrm{~m}^{3} /\left(\mathrm{m}^{2} \mathrm{~h}\right)$, the speed of the ascending air flow w varied from 0.5 to $3 \mathrm{~m} / \mathrm{s}$, and the water temperature supplied to the installation $t_{2}$ reached $30^{\circ} \mathrm{C}$.

The following method was used for hydroaerothermal testing of the cooling tower sprinkler. Water was sent to the hot water tank using a circulation pump, where it was heated by electric heaters to a temperature of $40^{\circ} \mathrm{C} \pm 1^{\circ} \mathrm{C}$ and fed through electro acoustic flow converters through a pressure pipeline to the water distribution system [18-20].

The water distribution system (irrigation density up to $\left.q=12 \mathrm{~m}^{3} /\left(\mathrm{m}^{2} \mathrm{~h}\right)\right)$ distributed the water flow over the irrigation area of the working section of the installation. The air flow directed towards it at a speed of $0.5 \ldots 3 \mathrm{~m} / \mathrm{s}$ was created by a centrifugal tangential fan. Air was supplied to the experimental unit through a tangential pipe located in the lower part of the body. The water, cooled in the facility, went to water collecting tank 7 and was supplied to tank 4 by the pump for next heating. The water cycle was closing.

During the experiments, the water temperature was recorded by a multifunctional device AMI-301 at the entrance and exit of the installation. During 15 minutes of operation of the unit (to warm up the system), the following parameters were set: water flow-by changing the speed of the pump engine and throttling, air flow-by opening

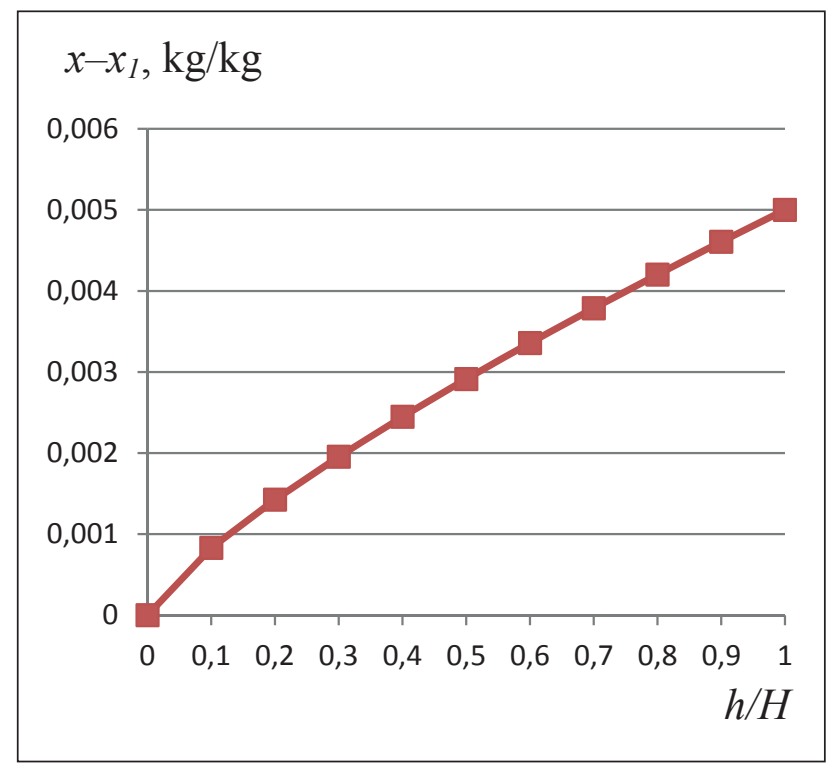

Fig. 3. Change in moisture content by height of the sprinkler

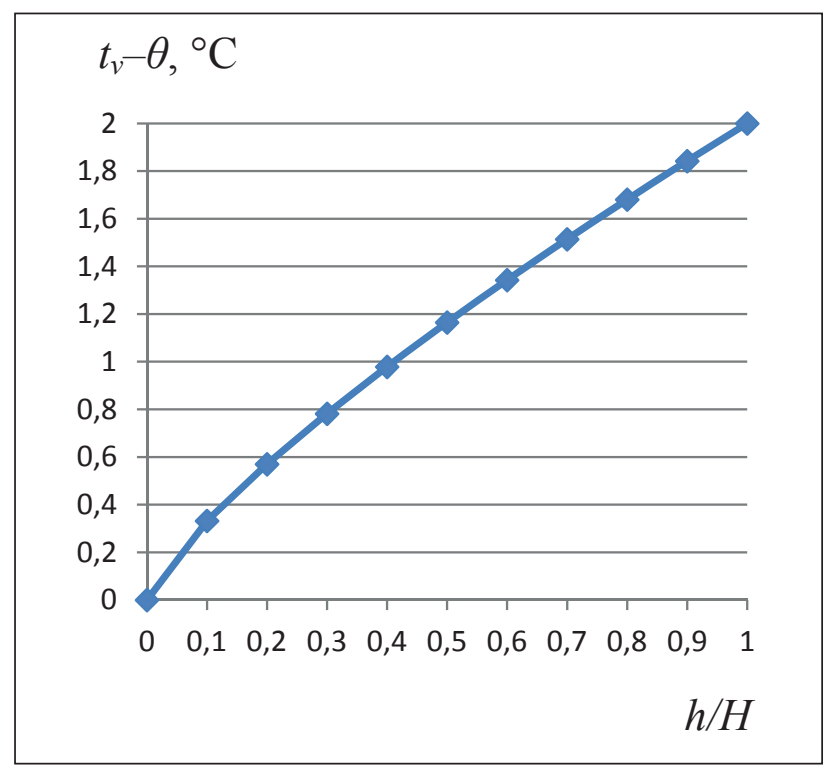

Fig. 4. Change in the air temperature drop along the height of the sprinkler 
and closing the gate valve, the speed was determined by the AMI-301 device. Atmospheric parameters, namely humidity and air temperature, were constantly monitored.

To measure the water temperature with the AMI-301 device, it was taken directly under the sprinkler with additional control with a mercury thermometer (TGL 11 998, accuracy class 1.66 , scale division 0.2 ), at the specified values of irrigation density $q$ and air flow. Then the waste water went to reservoir for heating, and the experiment was repeated for the next parameters of the irrigation density and air consumption [21, 22].

Studies to determine the Aerohydrodynamic characteristics were also carried out using the above method, but with the addition of measurements for pressure losses in the air flow before and after the sprinkler.

From the analysis of experimental data for the developed designs of cooling towers, it follows that the moisture content $\mathrm{x}$ and the air temperature $t_{v}$ in the volume of the height of the sprinkler changes according to a power law (and not according to a linear law, as was believed by other researchers).

$$
\begin{aligned}
& x(h)=x_{1}+k_{1} h^{a}, \\
& t_{v}(h)=\theta+k_{2} h^{b},
\end{aligned}
$$

where $k_{1}=\left(x_{2}-x_{1}\right) / H^{a} ; k_{2}=\left(t_{v 2}-\theta\right) / H^{b}$;

$$
0 \leqslant h \leqslant H \text {. }
$$

Constants $a$ and $b$ are found experimentally from the dependencies $x(h), t_{\mathrm{B}}(h)$ (Figures 3,4$)$ in logarithmic interpretation (Figure 5).
The curves in logarithmic coordinates represent linear dependencies, and the tangent of the slope angle corresponds to the exponents: $a=0.83, b=1.25$.

The mass transfer coefficient can be calculated from the given formulas:

$$
\beta_{x v}=\frac{G_{j} c_{j} \Delta t}{K\left\{\frac{\left(t_{v 2}-\theta\right)\left(c_{v c}+c_{p} x_{1}^{*}\right)}{b+1}+\left(r+c_{p} \theta\right)\left[\left(x_{2}^{*}-x_{2}\right)+\left(x_{1}^{\prime \prime}-x_{1}\right) \frac{a}{a+1}\right]+c_{p} \frac{\left(x_{2}^{*}-x_{1}^{\prime \prime}\right)\left(t_{v 2}-\theta\right)}{a+b+1}\right\}} .
$$

The mass transfer $\beta_{x v}$ and heat transfer coefficients $\alpha_{v}$ can be estimated from experimental data (tables 1 and 2).

The analysis of obtained dependencies allows making the following conclusions:

- mass $\beta_{x v}$ and heat transfer coefficient $\alpha_{v}$ of the researched twisted mini cooling tower at the equal densities of irrigation and rates of upward air flow rates of $2 \mathrm{~m} / \mathrm{s}$ exceed the countercurrent coefficients by $20 \%$;

Having starting since irrigation density $q=$ $8 \mathrm{~m}^{3} / \mathrm{m}^{2} \mathrm{~h}$, mass transfer coefficient $\beta_{x v}$ of twisted mini cooling tower has the greatest value and is kept at the same level.

To compare of recycled water cooling efficiency in a mini cooling tower with twisted air flow and countercurrent cooling tower, there were built comparative graphical ratios of the relative difference in water temperature from the air flow rate (Figure 6). The relative temperature drop of recycled water was determined by the formula:

$$
\eta=\left(t_{1}-t_{2}\right) / t_{1}
$$

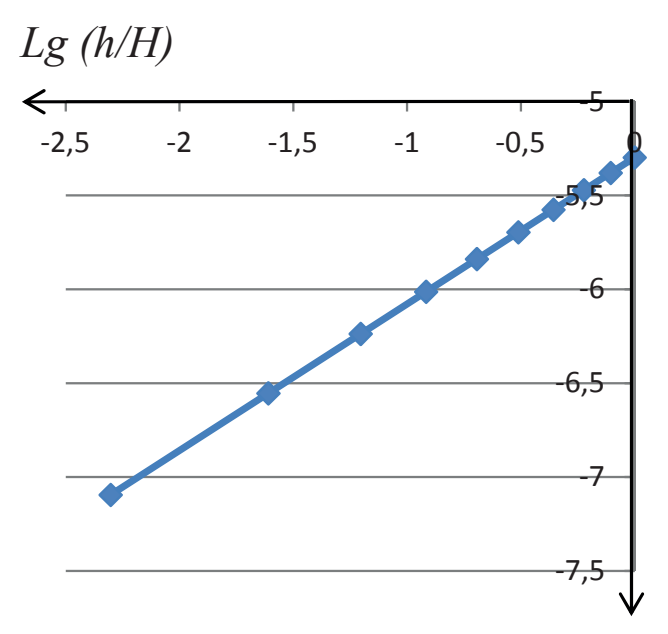

$\operatorname{Lg}\left(x-x_{1}\right)$

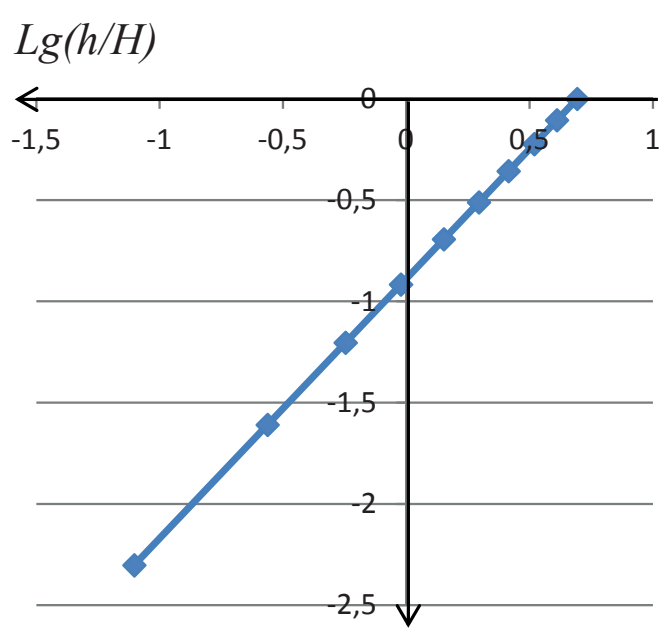

$\operatorname{Lg}(t-\theta)$

Fig. 5. Change in the difference in moisture content and temperature over the height of the sprinkler in logarithmic interpretation 
Table 1

Results of research on a laboratory installation of a mini-tower with a screw air flow

\begin{tabular}{|l|c|c|c|c|c|c|}
\hline № Experience's & $\mathbf{1}$ & $\mathbf{2}$ & $\mathbf{3}$ & $\mathbf{4}$ & $\mathbf{5}$ & $\mathbf{6}$ \\
\hline The density of irrigation $q, \mathrm{~m}^{3} / \mathrm{m}^{2} \mathrm{~h}$ & 2 & 4 & 6 & 8 & 10 & 12 \\
\hline Inlet air temperature $\theta,{ }^{\circ} \mathrm{C}$ & 14.2 & 14.2 & 14.2 & 14.2 & 14.2 & 14.2 \\
\hline Outlet air temperature $t_{v 2},{ }^{\circ} \mathrm{C}$ & 15.3 & 16.8 & 16.9 & 17.0 & 17.2 & 16.8 \\
\hline Ambient air humidity $\varphi_{1}, \%$ & 60 & 60 & 60 & 60 & 60 & 60 \\
\hline Humidity at the outlet of the cooling tower $\varphi_{2}, \%$ & 77 & 78 & 79 & 79 & 80 & 80 \\
\hline Change in air enthalpy $\Delta i, \mathrm{~J} / \mathrm{kg}$ & 15130.5 & 17150.3 & 17418.1 & 17611.7 & 18048.5 & 18048.5 \\
\hline Inlet water temperature $t_{1},{ }^{\circ} \mathrm{C}$ & 27.5 & 27.6 & 27.5 & 27.5 & 27.6 & 27.5 \\
\hline Outlet water temperature $t_{2},{ }^{\circ} \mathrm{C}$ & 20.0 & 18.9 & 18.0 & 17.8 & 17.7 & 17.7 \\
\hline Thermal power $Q, \mathrm{~W}$ & 6930.0 & 7946.4 & 8778.0 & 8962.8 & 9147.6 & 9055.2 \\
\hline Heat transfer coefficient $\alpha_{v}, \mathrm{~W} / \mathrm{m}^{3} \mathrm{~K}$ & 1534.4 & 1552.2 & 1688.3 & 1704.8 & 1708.5 & 1708.5 \\
\hline Mass transfer coefficient $\beta_{x v}, \mathrm{~kg} / \mathrm{m}^{3} \mathrm{~s}$ & 1.53 & 1.54 & 1.68 & 1.70 & 1.70 & 1.70 \\
\hline
\end{tabular}

Table 2

Results of research on the laboratory device of a mini cooling tower with a counterflow current

\begin{tabular}{|l|c|c|c|c|c|c|}
\hline № Experience's & $\mathbf{1}$ & $\mathbf{2}$ & $\mathbf{3}$ & $\mathbf{4}$ & $\mathbf{5}$ & $\mathbf{6}$ \\
\hline The density of irrigation $q, \mathrm{~m}^{3} / \mathrm{m}^{2} \mathrm{~h}$ & 2 & 4 & 6 & 8 & 10 & 12 \\
\hline Inlet air temperature $\theta,{ }^{\circ} \mathrm{C}$ & 14.2 & 14.2 & 14.2 & 14.2 & 14.2 & 14.2 \\
\hline Outlet air temperature $t_{v 2},{ }^{\circ} \mathrm{C}$ & 16.3 & 16.3 & 16.4 & 16.5 & 16.6 & 16.4 \\
\hline Ambient air humidity $\varphi_{1}, \%$ & 60 & 60 & 60 & 60 & 60 & 60 \\
\hline Humidity at the outlet of the cooling tower $\varphi_{2}, \%$ & 75 & 75 & 75 & 76 & 77 & 77 \\
\hline Change in air enthalpy $\Delta i, \mathrm{~J} / \mathrm{kg}$ & 17168.9 & 17168.9 & 18028.5 & 18444.1 & 18366.6 & 18028.5 \\
\hline Inlet water temperature $t_{1},{ }^{\circ} \mathrm{C}$ & 27.5 & 27.5 & 27.5 & 27.5 & 27.6 & 27.5 \\
\hline Outlet water temperature $t_{2},{ }^{\circ} \mathrm{C}$ & 21.5 & 20.2 & 19.6 & 19.4 & 19.6 & 19.6 \\
\hline Thermal power $Q, \mathrm{~W}$ & 5544.1 & 6837.6 & 7392.1 & 7207.2 & 7114.8 & 7207.2 \\
\hline Heat transfer coefficient $\alpha_{v}, \mathrm{~W} / \mathrm{m}^{3} \mathrm{~K}$ & 1081.7 & 1334.2 & 1359.4 & 1359.4 & 1356.7 & 1356.4 \\
\hline Mass transfer coefficient $\beta_{x v}, \mathrm{~kg} / \mathrm{m}^{3} \mathrm{~s}$ & 1.08 & 1.33 & 1.35 & 1.35 & 1.35 & 1.35 \\
\hline
\end{tabular}

The analysis of the obtained dependences as a result of experimental studies allows us to draw the following conclusions:

- for the studied small-sized cooling towers in the range of upward air flow speeds up to $0.7 \mathrm{~m} / \mathrm{s}$, the relative difference in water temperature for screw and countercurrent cooling towers differs slightly;

- in the range of air flow rates since 0.8 to $2.4 \mathrm{~m} / \mathrm{s}$, there is an increase in the value of the relative temperature drop of water in a mini-tower with a helical flow relative to the countercurrent;

- at the further increase of air flow rate, the efficiency of the spiral mini cooling tower exceeds the countercurrent $\sim 23 \%$.
During aerodynamic tests, the coefficient of aerodynamic resistance $\xi$ was calculated using the Weisbach formula.

From experimental data, it follows that in the range of air flow velocity of $0.5-3 \mathrm{~m} / \mathrm{s}$ and irrigation density of $0-12 \mathrm{~m}^{3} /\left(\mathrm{m}^{2} \mathrm{~h}\right)$, the coefficient $\xi$ values for the investigated nozzle devices of a mini-tower with a screw flow and a counter-current mini-tower are in the range 12 to $24 \mathrm{~m}^{-1}$.

Thus, the dependence of the coefficient of aerodynamic drag on the air flow velocity for the studied designs of sprinklers can be represented as:

$$
\lg \xi=\mathrm{K}_{1}-\mathrm{K}_{2} \lg R e,
$$




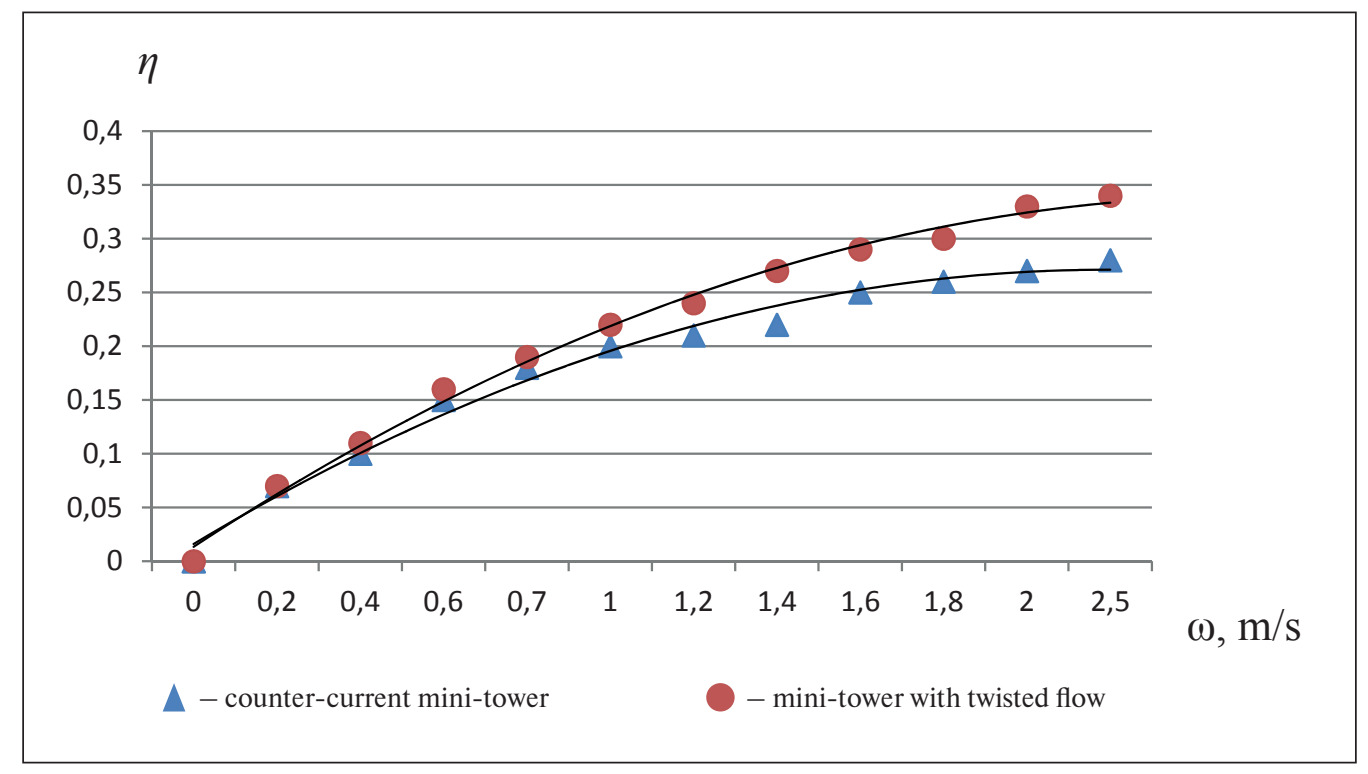

Fig. 6. Dependence of the relative temperature drop of recycled water on the air flow velocity

where $\xi-$ is the coefficient of aerodynamic drag of the sprinkler, $\mathrm{m}^{-1}$;

$R e$ - Reynolds number;

$\mathrm{K}_{1}, \mathrm{~K}_{2}$ - coefficients.

The General formula for determining the coefficient of aerodynamic drag depending on the Reynolds criterion for irrigation densities of $0-12 \mathrm{~m}^{3} /\left(\mathrm{m}^{2} \mathrm{~h}\right)$ is as follows:

$$
\xi_{1}=\mathrm{e}^{2,3 \mathrm{~K}_{1}} / \operatorname{Re}^{\mathrm{K}_{2}}
$$

where $e-$ is the base of the natural logarithm;

$\mathrm{K}_{1}, \mathrm{~K}_{2}-$ coefficients.

\section{CONCLUSIONS}

1. The designs of small sized devices of recycled water cooling with drop-film sprinkler of polymeric materials have been developed. The use of these devices will make it possible to increase an efficiency of nanotechnological process of mass-heat transfer on molecular stage

2. To carry out aerodynamic and hydro aero thermal tests of screw of small-sized device for recycled water cooling an experimental facility has been made. It was also determined the theoretical dependence of rotational and vertically translational parameter of the air flow rate on the height of the cooling tower. It is shown that rotational parameter decreases as the height increasesin accordance with exponentially law, and the vertical component increases according to the power law with the exponent $\sim 1,79$.

3. It was determined that the moisture content $x$ and air temperature $t_{v}$ in the volume of the height of the sprinkler $h$ varies according to a power law, in particular for a screw cooling tower proportionally $h^{0,83}$ (for the moisture content), $h^{1,25}$ (for air temperature). It was determined that the coefficients of mass transfer $\beta_{x v}$ and heat transfer $\alpha_{v}$ of a screw mini-tower at the intermolecular level with equal irrigation densities are $20 \%$ higher than the coefficients of a counter-current mini-tower.

4. It was revealed experimentally a dependence of aerodynamics resistance coefficient of the twisted irrigator of the cooling tower on criterium $R e$ for air flow $R e^{-K_{2}}$, and determined that it decreases as the exponent $\mathrm{K}_{2}$ varies in the range $0.114 \div 0.193$ depending on the irrigation density.

\section{REFERENCES}

1. Ivanov S.P., Ibragimov I.G., Bondar K.E., Ivanov O.S. Improving the efficiency of heat and mass transfer processes in water circulation cycles of industrial enterprises. Chemical and oil and gas engineering. 2014;12: 31. (In Russian). 
2. Ivanov S.P., Ibragimov I.G., Bondar K.E., Ivanov O.S. Experimental facility for research of hydroaerothermal characteristics of sprinklers and water catchers of cooling towers. Chemical and oil and gas engineering. 2015;1: 3. (In Russian).

3. Abramov N.N. Water supply: textbook for Universities. $3^{\text {rd }}$ edition. Moscow: Stroizdat; 1982.

4. Goncharov V.V. New technical solutions for tower and fan cooling towers. Chemical engineering. 2006; 6: 15-18.

5. Design features of the Dewdrop cooling tower. Available from: https://tecopro.ru/

6. Solovyov A.A. Improving the efficiency of using low-potential heat in energy production.Modern science and innovation. 2017; 3 (19): 140-146.

7. Fedyaev V.L., Bogatkin V.I., Vlasov E.M. Improvement of evaporative cooling towers for recycling water supply systems for industrial enterprises. Power Engineering of Tatarstan. 2011; 2: 44-47. (In Russian).

8. Pushnov A.S., Sokolov A.S., Butrin M.M. Methods for intensifying the process of heat and mass exchange in column apparatuses with contact devices. Bulletin of the Moscow State Technical University MAMI. 2013; 1 (15): 237242. (In Russian).

9. Bondar K.E., Ivanov O.S. Improving the design of water catchers for industrial cooling towers to reduce chemical emissions into the atmosphere. In: Geology and oil and gas potential of the West Siberian megabasin (experience, innovations): Proceedings of the Ninth International scientific and technical conference. ed. by O.A. Novoselov. Vol. 2. Tyumen: Tyumen State Petroleum Technological University; 2014. p. 250-252.

10. Bondar K.E., Ivanov O.S. Improving the designs of water traps in order to reduce droplet entrainment from industrial cooling towers. Low-waste, resource-saving chemical technologies and environmental safety: collection of materials of the All-Russian scientific and practical conference with international participation. Sterlitamak: Phobos; 2013. 223.

11. Bondar K.E., Ivanov S.P., Laponov S.V., Ibragimov I.G., Ivanov O.S. Forming extrusion equipment for the production of a mesh shell.In: Modern technologies in the oil and gas industry-2014: Proceedings of the international scientific and technical conference, 2 vols. Vol. 2. Ufa: Arkaim; 2014. p. 65-69.

12. Ivanov S.P., Bondar K.E., Suleymanov D.F., Shulaev N.S., Ibragimov I.G. Cooling tower sprinkler. Utility model patent RF 147330.2014-11-10.

13. Ivanov S.P., Boyev E.V., Storozhenko V.N., Izmailov S.P., Gerasimov V.V., Ryzhakov G.G., Lezhnev M.L. Cooling tower sprinkler. Patent RF 2295685. 2007-03-20.

14. Alexandrov D.V. Applied hydrodynamics. Moscow: Yurayt; 2018.

15. Bondar K.E., Shulaev N.S., Suleimanov D.F., Ivanov S.P., Podtspnyak E.S. Distribution of air flow rates in a small-sized cooling tower with tangential air supply. Natural and technical Sciences. 2019; 11: 411-414.

16. Bondar K.E., Ivanov S.P., Ibragimov I.G. and et al. Small-sized cooling tower. Patent RF 182965. 2018-09-06.

17. Ivanov S.P., BondarK.E., SuleymanovB.A. et al. Cooling tower sprinkler. Patent RF147330. 2014-11-10.

18. Ivanov S.P., Ibragimov I.G., Bondar K.E., Ivanov O.S. Experimental facilities for research of hydroaerothermal characteristics of sprinklers and water catcher cooling towers. Chemical and oil and gas engineering. 2015; 1: 3-5.

19. Bondar K.E. Technique carrying out of hydro aero-thermal and aerohydrodynamic tests of sprinkler of tubular mini cooling tower. In: Modern technologies in education and industry: from theory to practice: Collection of materials. Intra-university scientific and practical conference. Ufa: Oil and Gas Business; 2018. p. 158-159.

20. Ivanov S.P., Boev E.V., Nikolaev E.A. Method of hydroaerothermal testing of cooling tower sprinklers. Technique and technology. 2007; 3: 118-119.

21. Kluyko V.V., Kholpanov L.P. Research and calculation of hydrodynamic characteristics of regular contact devices in mass transfer columns. Chemical and oil and gas engineering. 2004; 5: 19-23.

22. Kalatuzov V.A. Improving the available capacity and efficiency of Perm CHPP-14 by reconstructing cooling towers. Refining and petrochemicals. 2004; 8: 17-20.

\section{INFORMATION ABOUT THE AUTHORS}

Kristina Y. Bondar, Senior Lecturer of the Department «Facilities of Petrochemical Plants», Ufa State Petroleum Technological University, Sterlitamak Branch, Sterlitamak, Russia, ORCID: https://orcid.org/0000-0002-9754-5335, e-mail: kristina88_08@mail.ru

Nikolay S. Shulayev, Dr. Sci. (Eng.), Professor, Head of the Department of «Computer Science, Mathematics, Physics», Ufa State Petroleum Technological University, Sterlitamak Branch, Sterlitamak, Russia,

ORCID: https://orcid.org/0000-0002-3595-6948, e-mail: nshulayev@rambler.ru 
Sergey P. Ivanov, Dr. Sci. (Eng.), Associate Professor of the Department «Equipment for Petrochemical Plants», Ufa State Petroleum Technological University, Sterlitamak Branch, Sterlitamak, Russia, ORCID: https://orcid.org/0000-0002-0642-2541, e-mail: isp-777@yandex.ru

Sergey V. Laponov, Cand. Sci. (Eng.), Associate Professor of the Department «Equipment for Petrochemical Plants», Ufa State Petroleum Technological University, Sterlitamak Branch, Sterlitamak, Russia, ORCID: https://orcid.org/0000-0001-8195-6474, e-mail: laponows92@mail.ru

\section{Authors declare the absence of any competing interests.}

Received: 14.10.2020.

Revised: 24.11.2020.

Accepted: 28.11.2020. 